\title{
TRES HUMORISTAS EN BUSCA DEL TEATRO: MIHURA, LÓPEZ RUBIO Y NEVILLE HACIA 1950
}

\author{
Víctor Garcia Ruiz \\ Universidad de Navarra
}

No hay que insistir en que el cine fue una experiencia fundamental en ese grupo de autores teatrales que lograron dar la vuelta al concepto y a la práctica del humor en España, entre -digamos- 1930 y 1950. Creo que lo mejor sería llamarlos «los humoristas», marbete plano pero elocuente, mejor que «otra generación del $27 »$, sugerente, sí, y enaltecedor, pero que llega más bien tarde: precisamente es ahora cuando la historiografía anda buscando sustitutos al viejo letrero gongorino; asociarse a él ahora resulta un tanto desgraciado. La asociación con la Vanguardia que alguna vez se ha practicado es, puestos a ser rigurosos, algo desmesurada. Claro que participaron del «espíritu de la vanguardia», pero me parece inexacto afirmar que, estrictamente, escribieron un teatro de vanguardia con una revolución formal paralela a la pintura o la escultura de vanguardia que algunos amigos suyos estaban realizando en esos mismos años.

El cine les dio experiencias de variado tipo: en primer lugar, la experiencia del viaje, sin la que seguramente no existirían novelas como Don Clorato de Potasa (1929) de Neville y iEspérame en Siberia, vida mía! (1930) de Jardiel -de quien se cuenta que se hacía enviar de los amigos postales de hoteles y ambientes lujosos para luego emplearlas en acotaciones de comedias o en descripciones de novelas-. En segundo lugar, la experiencia de Estados Unidos, un país sin hacer, que se vinculaba inmediatamente a la idea de Lo Nuevo, donde convivían razas, lenguas y religiones distintas, cosa inédita para un español; donde la riqueza estuvo 
al alcance de la mano hasta que cayó en una Depresión que, paradójicamente, se terminó convirtiendo en uno de los mitos unificadores de la conciencia nacional -por eso se escribe con mayúsculas. No sé hasta qué punto pudieron percibir la Depresión nuestros deslumbrados humoristas, que no se caracterizaron por una especial sensibilidad hacia lo social y que casi no frecuentaron otros ambientes que la enloquecida industria cinematográfica: productores implacables, actrices divinas, costumbres más libres y deportivas y un chorro de dinero tan abundante como inestable para unos jóvenes que nunca habían tenido un salario y que procedían de un país que, regido por una dictadura militar, iniciaba su modernización industrial. Ellos venían -como mínimo- de familias españolas burguesas con códigos de conducta distintos de los que regían en Hollywood. Estados Unidos les supuso el descubrimiento de otra sensibilidad y otra forma de vivir; incluso para Jardiel, el más impermeable y monolingüe del grupo. El problema debió de ser la vuelta a España, el «viejo país ineficiente» que evocó el memorable poema de Gil de Biedma en Las personas del verbo; y no digamos, años más tarde, el franquismo, aunque el tiempo y el trauma de la guerra seguramente mitigarían los contrastes.

$\mathrm{Y}$, en tercer lugar, el cine les permitió trabajar como guionistas en Hollywood, trabajo que consistía en escribir las versiones castellanas de los diálogos de películas que se juzgaban interesantes para el mercado mundial en lengua española y que se volvían a filmar de nuevo, normalmente con actores hispanoamericanos. La experiencia de escribir cine, es decir, el diálogo y la misma narración cinematográfica vista desde dentro, tuvieron que suponer un aprendizaje estético, ${ }^{1}$ un hiato respecto a las tradiciones del lenguaje teatral español, que se sumaba a otros factores modernizadores autóctonos que, resumiendo mucho, suelen desembocar en Ramón Gómez de la Serna y Ortega y Gasset.

Mihura no viajó a Estados Unidos porque estaba enfermo. No obstante, la experiencia del cine fue igualmente importante para él y, al igual que López Rubio y Neville, se dedicó a la industria cinematográfica española durante los años 40 , y antes. ${ }^{2}$ A comienzos de los 50 , al igual que los otros dos colegas, la abandonó para «pasarse» al teatro, actividad en la que los tres se habían iniciado en los años 30 .

1. Que yo sepa, está por estudiar con detalle la labor de cada uno de ellos en sus años de Hollywood: qué películas dialogaron cada uno de ellos, qué tipo de películas eran, qué aportaron respecto a las versiones primitivas, qué pudieron aprender.

2. Ver Ríos 2003, 41-79; Lara y, para el cine de Neville, Torrijos 1999. 
Estas páginas pretenden explorar el regreso al teatro, casi simultáneo, hacia 1950, que hicieron estos tres humoristas decepcionados del cine, ese icono de modernidad que modeló su juventud pero que no resistió las limitaciones económicas, las estrecheces ideológicas y los moldes estéticos del cine español de los cuarenta.

Además de hablar de lo mal que iba el cine español, esta reinserción teatral también pone de manifiesto la situación del teatro español hacia 1950, y en especial, el callejón sin salida a que había llegado el Teatro de Humor, ese humor de nuevo cuño en cuyo nacimiento habían participado Mihura, López Rubio y Neville. Al «volver a casa» los tres se encontraron con que «su» humor estaba a punto de cometer, si no lo había cometido ya, el gran pecado: mecanizarse, volverse tópico. ${ }^{3}$ Por eso terminaron orientándose hacia un cierto tipo de nueva comedia urbana, que surgía entonces, más o menos europea, que combinaba ingenio, humor, poesía, imaginación, algo de fantasía y un poco de sátira de costumbres. Los fugitivos del humor se refugiaron en la comedia. Veamos.

\section{López Rubio, el primero en volver}

Se lo dijo Jardiel en una carta de hacia 1950: «Debías lanzarte a hacer teatro solo y dejar el cine a los que no saben hacer otra cosa, que es para quien existe» (Torrijos 2003, 231). Y así lo hizo. Entre 1949 y 1955 José López Rubio (1903-1996) estrenó una decena de obras que concentran lo mejor de su teatro, además de una importante aportación a la recepción del teatro anglosajón en España. ${ }^{4}$ Entre sus versiones hay que destacar un verdadero hito del teatro de posguerra, La muerte de un viajante de Arthur Miller, que dirigió José Tamayo (Comedia, 10-I-52). Todo ello revela una clara decisión de olvidar el cine y dedicarse al teatro.

3. En Ríos (2005) puede verse un original ensayo sobre la naturaleza y los mecanismos del humor en el cine y el teatro españoles del siglo $\mathrm{xx}$.

4. La actividad como traductor de López Rubio en estos años fue muy intensa: El burgués gentilhombre (Español, 6-V-48), La loba (Español, 7-VII-50) de Lilian Hellman, El tiempo dormido (Español, 23-V-47) de Benn W. Levy. Prolongando la elegancia anglosajona del María Guerrero de Luis Escobar, ya algo manida a la altura de 1950, tradujo Plaza de Berkeley (María Guerreo, 12-IV52) de John L. Balderston y J.C. Squire, y, más policíaca, Crimen perfecto de Frederik Knott (María Guerrero, 17-4-54). Para el Beatriz hizo Sor Buenaventura, de Charlotte Hastings (22-12-50). No desdeñó la comedia centroeuropea con Liliom (María Guerrero, 7-X-55) de Ferenc Molnar y Europa y el toro (Alcázar, 10-IX-53) de Ladislao Fodor. En la línea del musical estuvo Al sur del Pacifico (Zarzuela, 25-I-55), también dirigida por Tamayo, original de Hammerstein, Logan y Rodgers. 
Entre los temas centrales que presenta el teatro de López Rubio destaca el papel de la ilusión en la vida humana, ${ }^{5}$ asunto que me parece legítimamente emparentable con los intereses contemporáneos de un autor como Buero Vallejo, aunque el tratamiento de uno y otro sea muy distinto, como es obvio. Nada tiene que ver con Buero, en cambio, un segundo punto: el gusto de López Rubio por subrayar el aspecto lúdico del teatro, su dimensión de artefacto, la desrealización metateatral, junto a cierta teatralización de la vida de raíz pirandelliana. López Rubio profesa el sistema teatral basado en un tándem de diálogo y situación, que maneja como un insuperable maestro avezado en los resortes de la mejor comedia hollywoodiense, de donde López Rubio obtiene un fondo más bien cínico y un sentido del humor poco corriente en aquella España, que sólo lejanamente podemos emparentar con el de sus amigos Jardiel o Mihura -aunque fuera años más tarde el propio López Rubio quien se inventara, más o menos, lo de «La 'otra' generación del 27 » en su discurso de ingreso en la RAE en 1983. Frecuenta también lo inverosímil aunque con un fondo pudorosamente intelectual, y no al veloz y descarado modo jardielesco. Una agudeza más bien mordaz para la relaciones interpersonales brilla especialmente en el diseño de los personajes femeninos, que aparecen como expertas en el arte de la intuición y la manipulación. Me parece perceptible la presencia en López Rubio de una inquietud existencial e intelectual de fondo unamuniano, orteguiano, pirandelliano, aunque su talante más bien escéptico le lleve a tratarla tangencialmente, acogiéndose al género de la comedia y sin ponerla en el centro de su teatro, como hace Buero que, consecuentemente, se instala en el drama y la tragedia.

Roque Six, su excelente novela vanguardista -vanguardista, ma non troppo- publicada en 1927, me parece un primer caso de esta aleación de influencias e ideas: en este relato de reencarnaciones, Estados Unidos aparece ya como una referencia central en la historia del reverendo Farjeón, la más extensa y significativa de las cinco reencarnaciones que componen el volumen. La novela arranca como una irreverente banalización de uno de los grandes temas de la literatura universal, la Muerte. La mirada a la disolución de Roque como sujeto es gélida y se prolonga en una visión casi clínica de las sensaciones de su cuerpo moribundo; sin sentimentalismo alguno. Es justamente mientras Roque Fernández habita al reverendo de una remota villa de Nebraska cuando descubre el destino que Dios le ha preparado -que consiste en ser tonto- y Roque se empeña en morir.

5. Para este y otros aspectos de López Rubio, ver Holt, todavía el mejor estudio de conjunto; sobre Mihura y Neville ver, respectivamente, De Miguel y Burguera. 
Roque Six deja de ser una novela brillante y despreocupada para volverse lo que es: una obra seria acerca del destino eterno del hombre, la relación entre Dios y la criatura y otros asuntos conexos, en los que entreveo al precoz lector de El sentimiento trágico de la vida (1913). En suma: un tema hondamente unamuniano, con una envoltura deshumanizada a lo Ortega y Gasset.

López Rubio volvió, pues, como un semi-novel, que había estrenado en los años 30 y hecho alguna adaptación teatral en los $40:{ }^{6}$ su primera obra original en esta segunda época fue Alberto (María Guerrero, 29-IV49), una comedia que leída hoy resulta francamente inverosímil -claro que el autor también había escrito unos Cuentos inverosimiles (1924) y se sentía muy unido a Jardiel, el gran apóstol de lo Inverosímil-. Los habitantes de una acomodada pensión pierden a su patrona y deciden inventar un personaje, Alberto, que los mantenga unidos. La ilusión se «realiza» y llega al punto de tener una secretaria, Leticia, enamorada de él. Pero cunde el desencanto cuando Alberto es acusado de malas acciones y engaños. El poder de la ilusión no se cuestiona, sin embargo, puesto que esta «decepción» es una contra-ficción organizada por el dentista de arriba, realmente enamorado de Leticia.

La casualidad quiso que inmediatamente después de Historia de una escalera siguiera en el Español Celos del aire (25-I-50), la obra más célebre de López Rubio. El primer acto de Celos del aire llevaba escrito desde 1935 y el segundo se empezó a escribir en Méjico en 1938. No es extraño, pues, que la obra presente fuertes conexiones con la estética de la preguerra. El complicado mecanismo escénico entre los dos matrimonios jóvenes y el matrimonio de ancianos que les contempla metateatralmente, está orientado, con todas sus sutilezas, a poner de relieve todo lo que el teatro tiene de artefacto. Unas movedizas relaciones entre lo verdadero y lo fingido - las tres parejas se relacionan a base de engañar con el enredo y la verdad-, un planteamiento en que vida y teatro se confunden -Enrique es comediógrafo a la caza de situaciones teatrales, los ancianos contemplan a los otros personajes como espectadores de teatro-, la autoparodia de la comedia convencional -celos, adulterio-, eso es Celos del aire. El autor ha contado que torció el desenlace para evitar el adulterio como solución, lo cual quita acidez a la obra pero no anula su planteamiento esencialmente lúdico.

6. De la noche a la mañana (Reina Victoria, 17-1-29) y La casa de naipes (Español, 27-V-30; d. Cipriano Rivas Cherif), ambas en colaboración con Eduardo Ugarte. 
Habría que ver hasta qué punto la experiencia cinematográfica americana de López Rubio pesó en los dos primeros actos: el primero se dedica a mostrar que el fingido adulterio de Isabel y Bernardo, con el que intentan curar la manía celosa de Cristina, es un adulterio en toda regla; el segundo se centra en el contraataque de la cándida Cristina que culmina en una fingida «escena de amor» en que ella y Enrique se dicen en voz baja y tierna las provincias españolas para que la otra pareja se imagine que también son amantes. Todo este juego y contrajuego, puro diálogo sin acción, lo contempla un matrimonio de ancianos, propietarios venidos a menos, que admiten huéspedes pero que, para mantener su perdida dignidad, fingen que siguen siendo los únicos habitantes de la casa. El tercer acto-escrito diez años después-, el de la reconciliación, da campo a los ancianos, que rompen la ficción y teatralizan su propia historia de infidelidades ante los huéspedes, que pasan al papel de espectadores.

A continuación, ${ }^{7}$ estrenó cuatro obras de tono menor y dos comedias de mayor importancia, al borde del drama: después del magnífico éxito de Celos del aire en la temporada 1949-50, Veinte y cuarenta (Español, 8-2-51), dirigida por Cayetano Luca de Tena, parece un juego poco trascendente, aunque sin rozar lo trivial. Lorenzo es un director de cine muy corrido a sus cuarenta años que se enamora de Marga, una vecina de veinte, admiradora suya, que está decidida a que Lorenzo no inicie la retirada hacia la vida hogareña y continúe con ella la vida nocturna, los viajes, cócteles y demás mundanidades. El diálogo y las situaciones -centradas en la relación del hombre y la mujer, el amor, el matrimonio, la sicología del acostumbramiento- supera en calidad al juego un poco artificioso en que se deja implicar Lorenzo. El mundo del cine proporciona la ocasión para un lenguaje atrevidillo y para la sátira de las convenciones sociales burguesas, tan cara a los humoristas. Neville explorará con más detalle, en Veinte añitos (1954), las inestabilidades afectivas de los cincuentones y Felipe Sassone, en esta misma temporada 1950-51, obtendrá cierta atención para su comedia ;Yo tengo veinte años! Realmente la veintena se puso de moda.

Cena de Navidad (Comedia, 14-XI-51) es una peculiar versión del tema del Cuento de Navidad cuyo primer acto recuerda la convocatoria de El landó de seis caballos (1950), de su buen amigo Ruiz Iriarte. En ambas obras se reúnen azarosamente, al menos eso parece, gentes de distintos ambientes sociales de la España del momento. En Cena son un señor de excelentes maneras, que es el convocante, un nuevo rico-estraperlista, se

7. Dado el planteamiento sincrónico del presente trabajo, mantengo el orden cronológico. 
deduce enseguida-, una señorita -Laura, que resulta ser señora engañada por su marido-, una «señorita» que figura en el reparto como la Mala Mujer y, brevemente, la Buena Mujer, que trae a cuestas, en estupenda síntesis, el drama de la emigración rural. Lo de la onomástica, claro, recuerda a Tres sombreros de copa, que López Rubio conocía desde que Mihura se la dio a leer en 1932. La expectativa por esta convocatoria para gentes solitarias en Nochebuena cede el protagonismo a Laura y a su conflicto matrimonial cuyo relato es re-teatralizado como sobremesa por los mismos comensales; no se trata de una vuelta atrás en el tiempo sino de un deliberado juego en el presente. Finalmente sabemos que la inverosímil cena ha sido también un juego del marido de Laura, el distinguido señor convocante, para recuperar y pedir perdón a su esposa. Tiene un cierto interés teatral la evolución del estraperlista como personaje; al principio incurre en una serie de incorrrecciones sociales -brusquedad e impertinencias, como hace resaltar, con suave esnobismo, López Rubio-, pero a medida que avanza la acción cambia la perspectiva y esas pequeñas tachas hacen de él un personaje más cercano que la orgullosa mundanidad del encopetado marido. Aunque el matrimonio se componga, se impone una visión algo escéptica según la cual el adulterio va de soi en la vida matrimonial; tendrá que ser justamente la Mala Mujer quien haga una llamada a la fidelidad del amor y cumpla un papel ligeramente moralista. Las alusiones contemporáneas en torno al «ricachón»-sus compras al por mayor, su metimiento entre magistrados, el ser de todos conocido, la inmensa parentela rural que le pide empleo-debieron de tener buena recepción; incluso se le compara con los Estados Unidos (59), que como son ricos, siempre tienen razón.

Al mes siguiente se presentó Una madeja de lana azul celeste (Reina Victoria, 7-XII-51) que consiste en un duelo de mujeres entre Lucrecia y Clara, por Daniel, recién casado con la segunda; la rivalidad se completa con una vecina, también enamorada de Daniel. Pero nada de vodevil: además de la agudeza aplicada al desarrollo de situaciones de la vida diaria, lo mejor es la elegancia, originalidad e inteligencia con que el autor maneja el topicazo de la esposa que recupera al marido anunciando -en este caso, dando a entender con la ropa de niño azul celeste- la llegada de un hijo.

El remedio en la memoria (Reina Victoria, 28-XI-52), ya en la siguiente temporada, pensada y escrita para Tina Gascó, gira en torno al mundo del teatro y tiene como protagonista a una famosa actriz, Gloria Velarde, que entra en conflicto con su hija por dos motivos: el escaso amor maternal de la Velarde, dedicada a su divismo, y la competencia por el mismo hombre, Antonio, novio maduro de la hija y antiguo amor de la madre. López Rubio juega deliberadamente a la ironía de explotar todos los melodramatismos que ofrece la coyuntura y así acentuar el espesor 
teatral y metateatral de las situaciones, en especial la situación de la meritoria que «ensaya» una escena destinada por la Velarde a hacer creer a su hija que Antonio es su propio padre, engañando con una mentira que parece verdad. Se trata de una comedia sobre la sicología de los actores y las peculiares relaciones entre vida y teatro. Como resume Gerardo, el autor que le escribe las comedias a Gloria, el asunto es que «ante un hecho real, ante un problema verdadero, no has sabido qué hacer porque no tienes una sola experiencia que no sea teatral... has buscado el remedio en la memoria» $(60)$.

En las dos temporadas siguientes no solo se abandona el tono menor sino que nos encontramos dos de las mejores comedias de López Rubio en toda su carrera: La venda en los ojos y La otra orilla. La primera (Infanta Isabel, 3-III-54) es una excelente comedia que tiene como tema central el abandono de la realidad por la ilusión, una ilusión que sobrepuja la realidad en forma original y compleja. La familia de Beatriz, esposa abandonada que finge no saberlo, convierte su hogar en una casa de locos voluntarios para seguir la corriente a la maniática Beatriz, de donde surgen varias situaciones inolvidablemente hilarantes en la línea del mejor Mihura o Jardiel. No obstante, va abriéndose paso una auténtica angustia que culmina con el regreso del marido; entonces la chifladura de Beatriz da paso a una terrible verdad: «Beatriz es ahora una mujer distinta... A fuerza de pensar en ellas tantos años, sus palabras son precisas. Todo revela en ella una resolución hecha a fuego lento» dice la acotación (81): después de diez años de ficción, Beatriz emprende ahora cruelmente otra ficción en la que el marido ya no tiene espacio. La vuelta a la ficción creadora tiene mucho de condena. La transición de lo ligero a lo serio trae al recuerdo el caso de Roque Six, al igual que en la siguiente comedia.

A mí me parece que La otra orilla (Comedia, 4-XI-54) es una comedia fresca todavía hoy. La apariencia es de comedia policíaca, pero con una inverosímil situación de partida: una serie de personajes recién muertos en un crimen pasional asisten a todo lo que sucede a continuación. $\mathrm{La}$ presencia simultánea e incomunicada de vivos y muertos -situación que, por cierto, se puso de moda en el teatro español de esos años- permite a los difuntos conocer muchas verdades que les afectan. Más teatro dentro del teatro, pues. Bajo el aparente aspecto humorístico, todo este juego de teatralización deliberada deja al descubierto las hipocresías y los egoísmos crueles que nos rodean a diario. La situación imaginativa, irreal y fantástica de que parte la comedia revela la verdad, poco halagüeña, que se esconde en las relaciones humanas. Yo diría que La otra orilla es una versión moderna del «theatrum mundi», un Juicio Final adelantado que, en medio del juego entre la verdad y las apariencias, lleva a preguntarse: ¿cómo nos 
comportaríamos si fuéramos siempre conscientes de que alguien nos ve, de que la realidad no se agota en la apariencia? Hay poesía, hay nostalgia, hay melancolía punzante, acidez y una perspicacia algo despiadada para con las flaquezas de los seres humanos; el ajuste milimétrico de esos elementos tan heterogéneos es el gran acierto de esta singular comedia.

Del todo ocasional fue Estoy pensando en ti (Español 23-V-50), en un acto, nada más que un chispazo de acción sin encadenamiento, con solo un personaje y escenográficamente desnuda -«Sobra hasta lo imprescindible» dice la acotación, 229-. Las cartas que dicta Juan y las conversaciones telefónicas con su secretaria se mezclan con una impaciente conversación paralela -sus pensamientos- de Juan con su novia sobre un próximo encuentro. El juego teatral se descubre al final cuando aparece una secretaria en la oficina y entendemos que la novia no existe. La antiexplicitud me parece estimulante. La pieza era un homenaje a Guillermo Marín pero el actor falló en toda la línea; según un envenenado comentario de Baltasar Gracián, «siguiendo una costumbre inveterada -seguramente de sus años de cómico de la legua-, no se supo el papel y llevó su recitado de una manera premiosa y falsa. No hay actor peor en el mundo que el señor Marín cuando quiere hacernos pasar por su «simpatía» y su vis cómica. Todas las escenas que hacía con la imaginada secretaria nos demostraron que una temporada de Conservatorio no le vendría mal») (Índice de artes y letras 31 (julio 1950): 15).

\section{Vuelve Mihura con Tres sombreros de copa: la juventud se enardece}

Miguel Mihura ha relatado (2004) con detalle y humor su regreso al teatro en 1951, ya cansado del cine que le tuvo ocupado desde mediados de los años 40, y cómo inesperadamente se interpuso en sus planes Tres sombreros de copa, como un fantasma traído por el joven Gustavo Pérez Puig. Para Mihura lo realmente convincente de esta propuesta -Mihura había rechazado antes alguna otra tentativa- era que no se iba a enterar nadie, ya que el montaje lo haría el Teatro Español Universitario y se daría solo una función. Como es bien sabido, la función única (24-XI-52) en el Español, con decorados de Emilio Burgos, de esta comedia escrita en 1932 alcanzó un gran éxito entre el juvenil público y entre la crítica, que destacó a Juan José Menéndez y a Agustín González. La función se repitió seis dias después y un mes más tarde comenzó su presentación comercial en el Beatriz (19-XII-52) de Luis Escobar-que le había hecho Ni pobre ni rico y El caso de la mujer asesinadita en su etapa del María Guerrero-, con Luis Prendes como actor; solo alcanzó 48 representaciones. En julio de 1957 se repuso en la Comedia y aguantó un mes. Mihura se dio cuenta 
de que la obra gustaba al público joven, a los grupos de teatro y a los actores jóvenes pero en cuanto se terminaban los jóvenes, el público «normal» rechazaba la comedia. La recepción del Premio Nacional de Teatro ese año acentuó el divorcio entre público minoritario y mayoritario frente a Tres sombreros. Hay, además, otro aspecto que el insatisfecho Mihura señala y es la «apropiación indebida» a que sus jóvenes admiradores tendían a someter la obra, exagerando el tono de farsa, la caricatura, lo burlesco, cuando el autor lo que deseaba ver reflejado era «el fondo íntimo de la obra» (50), «su parte poética y sentimental» (38).

Los jóvenes de los 50, encabezados por José Monleón, ${ }^{8}$ quisieron ver en Mihura un autor interesado por las realidades sociales, un rebelde vital y literario; pero creo que la mejor interpretación de Tres sombreros de copa es la que responde a las coordenadas culturales del humor de los años 20 y 30 . El ansia de escapar de lo cotidiano se concreta en la sátira de lo burgués, especialmente la boda establecida con señorita formal, como epítome de lo aburrido, lo consabido y lo moralmente asfixiante. Los artistas que arrastran a Dionisio durante una noche representan la libertad posible y no lograda. Tiene su importancia la referencia al jazz, música desenfrenada y negra, una especie de barbarie lícita en la Europa de los 20. Partiendo de una única situación inicial -los circenses toman a Dionisio por un malabarista al verle con los sombreros y él acepta pasivamente el equívoco- Mihura desarrolla todo un juego básicamente teatral en el que van quedando en evidencia las limitaciones de «lo normal», la irritante mediocridad del espíritu burgués identificado con el conformismo. Dionisio es un juguete a merced de una cadena de situaciones que se suceden con una lógica distinta a la habitual y con un lenguaje en el que nada es incoherente. El protagonista conmueve por la derrota que le acarrea su pasividad -esa es su marca-, una derrota en la que brilla la ternura y el anhelo poético de transfigurar lo de todos los días. Esta espléndida farsa, más que a un espíritu de rebelión y enfrentamiento, responde a un ansia, poética, de superar mediante el humor y la imaginación una realidad que ahoga.

El pesimismo que se desprende de Tres sombreros es más vital, caracteriológico, que filosófico; no procede de la radical negativa de la

8. «A Miguel Mihura nos lo apropiamos una generación que, por ser posterior a la suya, entrábamos en la vida nacional sobre supuestos y experiencias distintas... Tres sombreros de copa forjaron la idea de un autor interesado por las realidades sociales y por su evolución [...] Todas las represiones que Mihura dejó sueltas en aquella obra, y finalmente eran controladas, constituían una rebeldia vital, inconcreta si se quiere, literaria, pero profunda» (Monleón 44). 
angustia existencialista sino de la poesía de quien anhela y no logra trascender lo cotidiano. El lenguaje, lo mismo que el encadenamiento de las situaciones, es original porque responde a una lógica distinta de la común; y porque ridiculiza lo tópico, pero sin poner en cuestión la esencia comunicativa del lenguaje. A mi juicio, Tres sombreros de copa es un ejemplo sobresaliente del teatro como evasión de lo cotidiano. En cuanto a su supuesto absurdismo y vanguardismo, creo, muy en suma, que quien lo desee puede ver en Tres sombreros una obra del absurdo, un absurdo formal; pero en rigor, atendiendo a una interpretación global, no es tal cosa. $\mathrm{El}$ análisis London, que comparto, sugiere una coincidencia epidérmica y no de fondo con la vanguardia propiamente dicha. En cualquier caso, Tres sombreros de copa es la obra que hace de Mihura un autor imprescindible, sin que importe demasiado el resto de su producción. En su momento tuvo una repercusión de minorías pero después ha alcanzado, con toda justicia, un puesto sobresaliente en el canon del teatro español del siglo xx.

El caso de la señora estupenda (Alcázar, 6-II-53) fue la primera obra de Mihura deliberadamente escrita para el «teatro comercial o de consumo», el primer intento de su famosa «prostitución» $(2004,19)$, destinado a Lilí Murati, actriz húngara con fuerte acento, muy propio para la protagonista. Se hizo cargo de ella Cayetano Luca de Tena, que necesitaba estrenos para sacar adelante su compañía privada La Máscara. La comedia, al mismo tiempo de intriga y poética, se desarrolla en un hotel cosmopolita de la zona de los Balcanes, en un ambiente de guerra y refugiados. Victoria, después de intentar un matrimonio de conveniencia con Alejandro, es detenida como la espía Olga Tamarieff; pero es salvada, en todos los sentidos, por el encantador Carlos, al que se une, mientras caen las bombas y se hunde el mundo, una situación típica del individualismo sentimental y anarquizante de Mihura. Mientras Victoria y Carlos, la pareja vital y algo fantástica, se aman, Susana y Alejandro, los muy cursis, representan la vulgaridad, impermeables al peculiar clima poético de la otra pareja.

Muy poco después, Una mujer cualquiera (Reina Victoria, 4-IV-53) fue a parar al otro ex-director de Teatro Nacional cesado, Luis Escobar, también a la caza de comedias. Tras superar algunos problemas con la censura, la obra fue un gran éxito de público y de dinero para el autor. Procedía de un guión cinematográfico (1949) del propio Mihura y todavía sirvió para una nueva versión cinematográfica en 1955, la película argentina Pecadora. La comedia, no excelente, presenta dos puntos: el elemento policíaco de «cine negro» y el tema de la prostituta, muy del futuro teatro mihurano. Antes de salir del hampa para ingresar en el mundo respetable, un criminal que desea eliminar a un rival, contrata a una mujer cualquiera, Nieves, y se va con ella a casa de la víctima para que las pruebas recaigan 
sobre la chica. Pero Nieves y el asesino, enamorados, huirán juntos; cuando Nieves comprende que va a ser traicionada por segunda vez mata a su compañero: todo lo hizo «por miedo a estar sola... Lo hacemos todo por miedo a estar solas...» (62). La parte detectivesca perjudica el clima de la obra, que funcionó de cara al público.

A media luz los tres (Comedia, 25-XI-53), ya en la siguiente temporada, fue el éxito que «me decidió por fin a seguir haciendo el teatro que yo quería, no el «codornicesco» ni de vanguardia pero tampoco [sic] sin demasiadas concesiones, con humanidad, con ternura, con observación de personajes, con diálogo de calidad, sin pedanterías, humorístico y no arbitrario... me consagró como autor al que todos entienden» (Mihura 2004, 54-55). Solo había pasado un año desde el estreno de Tres sombreros. También es significativo que dirigiera él mismo a los tres actores del reparto, convencido de que solo él podía dar el tono exacto que sus comedias requerian. Por problemas de censura el título pasó de Piso de soltero al otro, más tanguero. Alfredo es un soltero conquistadorcete que logra traerse a su piso, una por acto, a una chica joven, una mujer casada y una cabaretera -las tres actuadas por Conchita Montes-; pero, como es un ingenuo, acaba felizmente casado con Paca, la criada -también la Montes-, porque cocina bien y le ríe las gracias. Un pieza cómica, epidérmica y «poca cosa», lejos del paradigma de la comedia mihurana, aún por llegar. En la misma temporada 53-54, Fernando Fernán-Gómez estrenó El caso del señor vestido de violeta (Comedia, 17-IV-54), con un primer acto muy gracioso, sobre un aristocrático torero que lee a Schopenhauer y tiene a Ortega retratado, pero que hace cosas muy raras porque padece un freudiano complejo de «viejecita» pues se hizo torero contra el criterio de su abuela. El frenesí jardielesco de acción y personajes más la expectativa funcionan francamente bien hasta que el torero confiesa su neurastenia; inmediatamente la comedia se hunde hasta convertirse en una farsa un poco tonta.

;Sublime decisión!, en cambio, es una buena comedia (Infanta Isabel, 9-IV-55) protagonizada por Isabel Garcés, situada en la galdosiana España de los cesantes y centrada en el papel de la mujer. Florita narra en off los antecedentes de su decisión sublime, que consiste en pedir trabajo en una oficina pública: así, tras asistir al ambiente de su modesto hogar de clase media y cursi, contemplamos la revolución que provoca su llegada al mugriento y machista negociado. Al final, todas las mujeres que la criticaron se irán a trabajar con ella cuando en el tercer acto se crea una oficina de solo mujeres. La obra es muy ingeniosa y rebosa talento cómico pero, por mucho que le irrite a Mihura, veo muchos chistes de La Codorniz prolongados periféricamente sin que termine de operar un centro poético rector. ¿Miedo a resultar sentimental? Porque la idea feminista, más que progresista, re- 
sulta curiosa, chocante, anticonvencional y con gran rendimiento teatral, pero los personajes no remontan mucho de su condición de monigotes. En su dimensión de teatro histórico cómico coincide con La guerra empieza en Cuba de Ruiz Iriarte, que se estrenará a fines del mismo año (18-XI-55), y alguna más.

En La canasta (Infanta Isabel, 1-XII-55) Mihura muestra su talento para la situación dramática $y$, en el fondo, nos ofrece una nueva versión del tema de Tres sombreros: la permanente insatisfacción del ser humano, su infelicidad crónica e incurable; también aporta la muy mihurana sátira del matrimonio y la familia, con sus chinchorrerías, y las egoístas manías del soltero. El primer acto es muy ingenioso y juega a la inversión de la expectativas: Laura, artista de cuplé, y Ramón parecen un cariñoso y apacible matrimonio de quince años de antigüedad que vive en un hotel, cuando Ramón propone a Laura que se casen, porque en realidad no lo están. Ella deja la canción, ponen casa y hacen vida de matrimonio moderno, con salidas nocturnas, juego de canasta... y su adulterio; es decir, destruyen su felicidad anterior. Finalmente cortan con arreglo tan respetable, se vuelven los dos al hotel y Laura regresa al escenario. La canasta, que procedía del guión cinematográfico Me quiero casar contigo, permaneció inédita hasta los años 90, no entiendo por qué, puesto que me parece sumamente representativa.

El retorno de Mihura culmina con Mi adorado Juan (Comedia, 11I-56; Premio Nacional de Teatro). Hasta entonces, el elemento humano, sentimental, poético, al que quería dedicarse, no terminaba de salirle, se le ahogaba aún entre sus otros recursos de ingenio y de diálogo, admirablemente manejados. Pero en Mi adorado Juan se aproxima de nuevo a la melancolía derrotada de Tres sombreros. Juan, en otro tiempo médico brillante, vive con extrema sencillez lo mismo que otros «bohemios»-de los que no desayunan huevos fritos- que también se retiraron de la lucha por la vida para, simplemente, vivir. Enfrente, el brillo de la vanidad, el éxito, el mundo del famoso doctor Palacios, que acaba traicionado por su mezquino ayudante. Y en medio, Irene, enamorada de Juan que, tras una crisis de lujo, vuelve a él pero haciéndole entender que una pasividad tan radical es destructiva. Mihura, proyectándose biográficamente con más claridad que en Tres sombreros, regresa al borde de lo sentimental farsesco, enfrenta lo razonable y lo disparatado, se vuelve algo casoniano en la creación de mentiras que hacen la felicidad y hasta recoge esa vaga aspiración de libertad en el motivo de la ventana por donde se ven los barcos; ese que tan brillantemente manejaba el hostelero don Rosario. En suma, es el camino hacia sus mejores comedias: Maribel y la extraña familia (1959) o La bella Dorotea (1963). 


\section{El triunfal y efímero regreso de Neville}

Cineasta de irregular mérito en la España de posguerra, pintor ocasional, antiguo colaborador en la línea progresista de la página teatral de $\mathrm{El}$ Heraldo de Madrid (1923-27), autor de la comedia Margarita y los hombres (Benavente, 9-II-34), narrador de humor ácido radicado en el odio a lo convencional, cosmopolita, aristócrata, diplomático «pero poco», y productor de anécdotas sardónicas, como no necesitaba del teatro para vivir, Edgar Neville (1899-1967) pudo permitirse una actividad discontinua y dispersa, además de un notable esnobismo. El problema de Neville como autor teatral es que su vida es bastante más interesante que su obra, en conjunto poco lograda, con un pico en El baile (1952) y un buen planteamiento, marrado luego, en La vida en un hilo (1959); el resto de su teatro me parece de orden menor. Neville trabajó poco, frivolizó demasiado y tenía poco que decir. Un autor que dictaba sus comedias a su secretaria y luego no las corregía se merece cien veces el reproche de su querida y fiel Conchita Montes: «iQue no rematas, Edgar, que no rematas!». No remataba porque le aburría ese tipo de trabajo; o sea, el trabajo.

Su mundo se reduce al tratamiento de un tema único del que hubiera podido sacar algo más importante: el tiempo y sus efectos en el hombre. Estos efectos son, en primer término, el tedio, el aburrimiento del presente; por aquí viene la sátira de la rutina, lo tópico, que llega a ser cruel cuando se trata de los convencionalismos de la clase media. En segundo término, el error existencial, el paso del tiempo como sucesión de elecciones que van condicionándonos sin posible rectificación ni vuelta atrás. En el teatro de Neville hay una romántica rebelión contra ese límite ontológico del ser humano. Su acre humor es síntoma de un peculiar inconformismo que quiere librarse de lo establecido a pequeña escala: el convencionalismo burgués, y de lo establecido a gran escala: la irreversibilidad del tiempo. De ahí, el amor otoñal, la melancolía y la frivolidad; es decir, la inmadurez. Su centenario en 1999 le deparó un muy digno volumen editado por José María Torrijos, con algunas aportaciones originales y poco más.

Neville vuelve al teatro triunfalmente con el inmenso éxito de $E l$ baile (Comedia, 26-IX-52). Desarrolla una situación completamente anticonvencional: una mujer con «dos maridos», el de verdad, que es indulgente, y el amigo, enamorado de ella, que es quien vela por la honra del matrimonio. Un singular «mundo al revés», con un toque sentimental cuando aparece la muerte y se lleva a Adela, la mujer que hizo posible un ideal de amor intacto tras veinticinco años, sin las huellas del roce cotidiano. Veinte años más tarde, la nieta Adela representa para los dos «viudos» la emotiva reactualización del pasado de aquel baile, cuando decide jugar su papel en el mundo que crean los ancianos: un mundo donde el tiempo no 
hace daño a los hombres ni marchita el amor, como en el mundo de todos los días. Una serie de elementos, hábilmente recurrentes -el tema del baile y la clámide, el escenario único, los celos de Julián y la simpática despreocupación de Pedro, la mesita dorada, la pulsera, la entomología- prestan lirismo a una farsa cuyo anhelo es consumar una peculiar protesta contra la realidad: el bolero Reloj, no marques la horas, puesto en escena. Dentro de un corto reparto de tres actores, Conchita Montes hace el papel de las dos Adelas, cosa que le gustaba bastante. Adelita (Comedia, 14-I-55) prolongaba las peripecias de la nieta de El baile, sin brillantez.

Con variable proporción de irrealismo, el resto del teatro de Neville insiste en la denuncia del tópico, la liberación de los convencionalismos, el humor como medio de rebeldía y la quimera de anular el tiempo. Es lo que hace Veinte añitos (Comedia, 9-II-54), intento de comedia fáustica, con diablo, que devuelve la juventud a Pepe y a Faustina, a vista del público, a cambio no del alma sino de un mechero y una polvera. Tras algunas peripecias algo picantes recuperan su vejez llenos de ilusión y deseos de felicidad en común.

Neville anduvo estos años dirigiendo algunas obras, entre ellas la versión de La dama de las camelias hecha por Conchita Montes y -cosa extraña- Fernández Ardavín (Comedia, 28-IX-55), notablemente orientada al lucimiento personal de la actriz, de sus joyas y figurines - que pueden admirarse en la revista Teatro $(17,1955)$-. En Marramiau (Teatro Zorrilla, Valladolid, 1954), Neville adapta a Ladislao Fodor y compone una comedia algo fantástica sobre un novelista americano y soltero, que no hace caso de Linda y sí de su gata Ofelia, la cual resulta ser reencarnación de una princesa egipcia con la que él, que en realidad es un camellero egipcio, lleva casado 2500 años. Da igual el asunto, el tema es, de nuevo, el tiempo y el amor. Con Rapto (estrenada en Ciudad Real, 1955) Neville intentó ponerse serio y crítico sobre el matrimonio y el papel de la mujer, partiendo de un nuevo «senex junior» aunque el personaje importante es la joven Mercedes.

La vida en un hilo (María Guerrero, 5-III-59) ofrece interés en su formulación narrativa y escenográfica, que procede del guión de la película, estrenada en 1945. Los distintos episodios de cada Parte -nada de actos- se suceden mediante telones con figuras simbólicas del tedio o de la felicidad y la risa. Hay escenas partidas, un taxi en escena, una sala de fiestas, variedad de espacios. En la obra se plantea el contraste entre lo creativo y lo convencional. Se simboliza esto último en el telón del tedio y se encarna en Ramón, el ingeniero de la posguerra, la seguridad económica, la vida en provincias, la formalidad, las visitas, el pacatismo moral, el acomodarse mecánicamente a patrones ajenos. Con el plúmbeo 
Ramón ha estado casada Mercedes, que contempla lo que podía haber sido su vida con Miguel Ángel si aquel día de lluvia hubiera aceptado el taxi que este le ofreció, en vez de aceptar el que le ofreció Ramón poco después. Porque Miguel Ángel, artista, es la alegría, la libertad, la imaginación, la ausencia de rigideces y, por encima de todo, el lenguaje agudo e inteligente. Teatralmente resulta efectivo el contraste liberador entre las saladísimas escenas que se desarrollan con Miguel Ángel y la feroz sátira del mundo de Ramón.

La vida en un hilo, que pierde mucho en la segunda parte y epílogo, es la versión nevilliana de un tema que los dos otros hijos pródigos del teatro -hermanos pródigos, más bien-, Mihura y López Rubio, habían tratado, ya en los años treinta, en Tres sombreros de copa y Casa de naipes.

\section{El contexto teatral de los tres regresos}

En otras ocasiones he querido llamar la atención sobre la importancia historiográfica que atribuyo a la fecha de 1950 como momento de cambio en el teatro de la posguerra; en cierto sentido, el primer cambio importante. ${ }^{9}$ A mi juicio, 1950 es el verdadero comienzo de la posguerra teatral, por la serie de factores que se agrupan:

a) El humor de estirpe jardielesca se encuentra en punto muerto. Jardiel agotó su ciclo a mediados de los 40 y pronto agotará su vida, en 1952. El ingenioso Tono aún prolonga con cierto talento, sobre todo lingüístico, el humor de Jardiel, aunque sin renovarse y reiterando en exceso unos mismos motivos. Es el caso de iQué bollo es vivir! (Infanta Isabel, 3-X50), Tilta Rufa (Barcelona, Comedia, 13-XII-50), Federica de Bramante (Infanta Beatriz, 22-XII-53) y una serie de colaboraciones - muy mala

9. «Muchas cosas cambian dramáticamente en España en 1939 , pero el teatro, a mi juicio, no es una de ellas. Casi todo sigue bastante igual en términos estructurales. Me parece que los años 40 son una década de liquidación de géneros, una etapa de derribo que se consuma hacia 1950, momento en que cuajan los cambios que tendrian que haber acaecido diez años antes. Para el teatro español en su conjunto [los 40 son] una década de retraso, de superabundancia y de confusión» (García Ruiz 2003, 15), seguida hacia 1950 por la «emergencia sólida de dos corrientes: una corriente trágica y otra de comedia culta. La primera la representa[n] Buero Vallejo..., los jóvenes autores del grupo Arte Nuevo, singularmente Alfonso Sastre, y cierto teatro norteamericano y francés ofrecido por los teatros de cámara... El establecimiento de una comedia culta de rango europeo tiene más larga historia y perfiles menos claros entre la «comedia de la felicidad» y la comedia de humor: me refiero a José López Rubio y Víctor Ruiz Iriarte, que tienen estrenos importantes en torno a 1950 -Celos del aire y El landó de seis caballos respectivamente» (García Ruiz 2004, 11-12). En Continuidad y ruptura en el teatro español de la posguerra (1999) me ocupo del relativo papel de la guerra civil como factor de ruptura en la evolución de nuestro teatro. 
señal- con Eduardo Manzanos (Un drama en el quinto pino; Benavente, 19-12-1950), Jorge Llopis (La viuda es sueño; Infanta Isabel, 3-XII-52) y Janos Vaszary (La verdad desnudita; Reina Victoria, 10-III-55).

Dedicado a una comicidad de menor rango que Tono, Álvaro de Laiglesia, director de La Codorniz, se vinculó a la pareja de húngaros Janos Vaszary y Lilí Murati. ${ }^{10}$ En solitario estrenó el juguete cómico Amor sin pasaporte (Reina Victoria, 30-I-53)

En un escalón cercano e inferior, Carlos Llopis prosigue su línea de años anteriores: La cigüeña dijo «sí», continuación poco brillante de la muy digna Nosotros, ellas y... el duende (Cómico, 10-I-52), con José Alfayate. Siguió La vida en un block (Comedia, 9-1-53) con la compañía de Fernando Fernán-Gómez, floja comedia que da cuenta del auge del folclore y las folclóricas en el Madrid de los 40 y 50 .;Nosotros también! (Cómico, 26-II-54), con José Alfayate y Rafaela Rodríguez, es un sainetón, mientras que ¿De acuerdo, Susana? (Cómico, 9-IV-55) es un sainete bien valorado por Marqueríe; mucho debió de contribuir al éxito Alberto Closas, que se presentaba en Madrid como primer actor y que triunfó plenamente. La distinguida Conchita Montes protagonizó $\mathrm{El}$ amor tiene su aquel (Comedia, 2-XII-55). No faltaron revistas y vodeviles: La cuarta de A. Polo (Lope de Vega, 31-V-51) o iAbracadabra! (Fuencarral, 13-II-53). Este teatro de Llopis nos deja ya a las puertas de Adolfo Torrado, que todavía pululaba con melodramas como Amoriños a dos velas (Infanta Isabel, 27-1-54), y de toda la masa del teatro cómico y saineteril, que seguía estirando ramplonas tradiciones de preguerra.

b) Víctor Ruiz Iriarte, con su Landó de seis caballos (María Guerrero, 26-5-50), El gran minué (Español, 8-12-50), Juego de niños (1952) y otras comedias como La soltera rebelde (Reina Victoria, 19-9-52) o El pobrecito embustero (Cómico, 4-4-53), obtiene una fórmula de comedia que, por un lado, exige rango literario y, por otro, tiene la gran virtud de ser polifuncional puesto que admite elementos variados como el humor, el ingenio, la ternura, la sátira social contemporánea, la farsa y también escapes hacia lo poético, lo fantástico o lo imaginativo. En suma, una comedia «fina», urbana, con ecos de la comedia europea, que en nuestros manuales se conoce como «comedia de la felicidad», «de la ilusión»o «de evasión».

10. Con ellos hizo en Barcelona Loló (Barcelona, 2-6-51); con Arturo Rigel una mala comedia musical: Peligro de Marte (Lope de Vega, 13-9-52), con Mihura un acto titulado El caso del señor que volvió del Polo (María Guerrero, 4-1-53), con Vaszary y el maestro Parada, otra comedia musical: El corderito verde (Lope de Vega, 4-4-53), digna pero nada original, además del juguetillo de risa Sirenas sin cola (Reina Victoria, 25-2-54), estrenado por la Murati, y la comedieta Amor de veinte quilates (Infanta Isabel, 18-10-54). 
En ella es fácil advertir la reunión de una línea autóctona que procede de Casona y un estímulo extranjero que llegó a nosotros a través de textos y puestas en escena contemporáneas del teatro extranjero de Jean Anouilh, Noel Coward o John B. Priestley.

c) Se estrena Historia de una escalera (Español, 14-X-49) y Buero Vallejo comienza a estrenar regularmente. Esta trayectoria coincide con la inquietud de hombres pertenecientes a una generación más joven que aspiran a un teatro de estética realista y comprometida con la crítica de la sociedad. Alfonso Sastre y José María de Quinto, con su frustrada iniciativa por un Teatro de Agitación Social (1950), sus frecuentes colaboraciones en las revistas culturales y los ocasionales estrenos del primero, son lo más representativo de esas nuevas aspiraciones, que ya estaban en el grupo Arte Nuevo (1946-48) y que prolongará la llamada Generación Realista. El teatro extranjero de signo trágico, Sartre, Miller y O'Neill especialmente, aportó la convicción de que se podía hacer un teatro diferente.

d) Agoniza la anacrónica figura de Benavente, apuntalado por algunos seguidores como Sassone, y actualizado por autores bien activos como Pemán, Luca de Tena y, con más matices, Joaquín Calvo Sotelo.

e) También en el entorno de 1950, menudean los grupos de cámara, se estrena el «Tenorio de Dalí» (María Guerrero, 1-XI-49), entran en crisis los Teatros Nacionales y José Tamayo, con sus montajes, ayuda a arraigar entre nosotros la figura del director de escena -cosa que no lograban Cayetano Luca de Tena y Luis Escobar desde fuera de los Nacionales-. En otro orden de cosas, arranca la revista Teatro (1952) y la colección Alfil de textos teatrales (1951).

Enfrentados a este panorama hacia la mitad del pasado siglo $\mathrm{xx}$, se comprende que a nuestros tres ex-cineastas no les quedaba otra alternativa que la comedia. Era lo único viable para su reincorporación al teatro, regreso que supone otro síntoma de que algo cambiaba en el teatro español de posguerra. Aquel nuevo humor que les había enseñado a mirar las cosas de otro modo quedaba descartado: era un trasto viejo con el que cualquiera podía jugar. El proteico y eterno género de la comedia, por su parte, ofrecía la posibilidad de seguir haciendo humor sin hacer "teatro de humor». Mihura buscó su sitio en la veta tierna y sentimental, López Rubio logró hacer algunas comedias con un cierto tono intelectual y Neville, tras la inesperada borrachera de El baile, no regresó nunca de la resaca. 


\section{BIBLIOGRAFÍA}

Burguera Nadal, Ma Luisa. Edgar Neville: entre el humorismo y la poesía. Málaga: Diputación Provincial, 1994.

- Edgar Neville entre el humor y la nostalgia. Valencia: Diputació-Institució Alfons el Magnànim, 1999.

De Miguel, Emilio. El teatro de Miguel Mihura. $2^{\text {a }}$ ed., Salamanca: Ediciones Universidad, 1997.

García Ruiz, Víctor. Continuidad y ruptura en el teatro español de la posguerra. Pamplona: Eunsa, 1999.

- «El teatro españcl entre 1939 y 1945». Historia y antología del teatro español de posguerra. 1, 1940-1945. Eds. Víctor García Ruiz y Gregorio Torres Nebrera. 7 vols. Madrid: Fundamentos, 2003. 11146.

- «El teatro español entre 1945 y 1950». Historia y antología del teatro español de posguerra. II, 1945-1950. Eds. Víctor García Ruiz y Gregorio Torres Nebrera. 7 vols. Madrid: Fundamentos, 2004. 11140.

Holt, Marion Peter. José López Rubio. Twas 553. Boston: Twayne, 1980. LARA, Fernando, y Eduardo Rodríguez. Miguel Mihura en el infierno del cine. Valladolid: Seminci, 1990.

LoNDON, John. «Miguel Mihura's Place in the Theater of the Absurd...». ALEC, 14 (1989): 79-96.

López Rubio, José. Cena de Navidad. Madrid: Alfil, 1951.

- El remedio en la memoria. Madrid: Alfil, 1952.

- La otra orilla. Madrid: Alfil, 1955.

- La venda en los ojos. Madrid: Alfil, 1954.

- Una madeja de lana azul celeste. Madrid: Alfil, 1952.

- Veinte y cuarenta. Estoy pensando en ti. Madrid: Publicaciones Españolas, 1951.

- y Eduardo UGARTE. De la noche a la mañana. La casa de naipes. Madrid: Alfil, 1958.

Minura, Miguel. A media luz los tres. Madrid: Alfil, 1954.

- Miguel. «Introducción». Tres sombreros de copa. Maribel y la extraña familia. 1977. Ed. revisada y actualizada por Juan A. Ríos Carratalá. Madrid: Castalia, 2004. 13-69.

- El caso de la señora estupenda. 1953. $3^{\mathrm{a}}$ ed. Madrid: Alfil, 1967.

- El caso del señor vestido de violeta. Madrid: Alfil, 1952.

- La canasta. Vigo: Cardeñoso, 1998.

- ;Sublime decisión!. Madrid: Alfil, 1955.

- Teatro completo. Madrid: Cátedra, 2004. 
- Tres sombreros de copa. Ni pobre ni rico, sino todo lo contrario. El caso de la mujer asesinadita. Madrid: Editora Nacional, 1947.

- Una mujer cualquiera. Madrid: Alfil, 1953.

Miller, Arthur. La muerte de un viajante. Tr. José López Rubio. Madrid: Alfil, 1952.

Monleón, José. Pról. a M. Mihura. Teatro. Ed. José Monleón. Madrid: Taurus, 1965.

Neville, Edgar. Margarita y los hombres. Madrid: Alfil, 1969.

- El baile. Madrid: Alfil, 1956.

- Teatro selecto. Madrid: Escelicer, 1968 [contiene Veinte añitos, El baile, Rapto, Prohibido en otoño, La vida en un hilo, Alta fidelidad].

Torrijos, José Ma, ed. Edgar Neville (1899-1967): la luz en la mirada. Madrid: INAEM, 1999.

- ed. José López Rubio. La otra Generación del 27: discurso y cartas. Madrid: Centro de Documentación Teatral, 2003.

Real ACAdemia Española. La otra generación del 27: discurso leído el día 5 de junio de 1983, en su recepción pública, por el Excmo. Sr. Don José López Rubio, y contestación del Excmo. Sr. Don Fernando Lázaro Carreter. Madrid: s.p., 1983 [reproducido en Torrijos 2003, 41-871.

Ríos Carratalá, Juan A.. Dramaturgos en el cine español (1939-1975). Alicante: Publicaciones de la Universidad de Alicante, 2003.

- La memoria del humor. Alicante: Publicaciones de la Universidad de Alicante, 2005. 